\title{
Description of a New Scaled Species of Ptychostomella (Gastrotricha: Macrodasyida) from the Brazilian Coast and a Cladistics Analysis of the Genus
}

\author{
Thiago Q. Araújo *(D) and André R. S. Garraffoni $\mathbb{D}$
}

\author{
Department of Animal Biology, Institute of Biology, University of Campinas, Campinas 13083-970, SP, Brazil; \\ arsg@unicamp.br \\ * Correspondence: araujotq@gmail.com
}

Citation: Araújo, T.Q.; Garraffoni, A.R.S. Description of a New Scaled Species of Ptychostomella (Gastrotricha: Macrodasyida) from the Brazilian Coast and a Cladistics Analysis of the Genus. Taxonomy 2021, 1, 278-289. https://doi.org/10.3390/ taxonomy1040022

Received: 4 August 2021

Accepted: 1 October 2021

Published: 8 October 2021

Publisher's Note: MDPI stays neutral with regard to jurisdictional claims in published maps and institutional affiliations.

Copyright: (c) 2021 by the authors. Licensee MDPI, Basel, Switzerland. This article is an open access article distributed under the terms and conditions of the Creative Commons Attribution (CC BY) license (https:/ / creativecommons.org/licenses/by/ $4.0 /)$.

\begin{abstract}
A new species of marine Gastrotricha from the north coast of São Paulo state, Brazil, is described. Adults of Ptychostomella sebastiana sp. nov. are unique in that they possess a pair of dorsolateral "rod-like" cephalic sensory organs and subrectangular scales covering the lateral body surfaces. A cladistic analysis was performed to investigate the internal relationship of the representatives of the taxa based on morphological data. Our analysis supported the monophyly of the taxon Ptychostomella, but its internal phylogenetic relationships are not well established due to the low phylogenetic signal of morphological characters used in the present study.
\end{abstract}

Keywords: Gastrotricha; morphology; phylogeny; macrodasyida

\section{Introduction}

The family Thaumastodermatidae is the most specious and diverse group of Macrodasyida and comprises eight genera and up to 140 described species [1,2]. Specimens of this taxon are usually recognized by the diversity of cuticular ornamentations of the dorsal and ventral surfaces (e.g., scales, spines, spined scales, ancres).

Belonging to this taxon, specimens of the genus Ptychostomella Remane, 1926 were originally recognized by their smooth cuticle, large oral hood, and lateral club-shape or knob-like tentacle. Some authors have hypothesized that the lack of ornamentation is a secondary reduction $[1,3,4]$. This panorama changed when the first specimen of Ptychostomella with cuticular ornamentation was described, P. lepidota Clausen, 2000. Since then, another four ornamented species have been described: P. orientalis Lee \& Chang, 2003, P. brachycephala (Levi, 1954), P. papillata Lee and Chang 2003, and P. lamelliphora Todaro 2013.

In this study, we describe a new species of Ptychostomella with cuticular ornamentation collected on the Brazilian Coast and present the first phylogenetic hypothesis using external morphological data to investigate the internal relationship of the taxon Ptychostomella.

\section{Materials and Methods}

\subsection{Sampling}

Samples were obtained (22/02/2018) at São Sebastião Island (where the municipality of Ilhabela is housed) at Fome Beach $\left(23^{\circ} 44^{\prime} 27^{\prime \prime} \mathrm{S} ; 45^{\circ} 16^{\prime} 01^{\prime \prime} \mathrm{W}\right)$. The top $10-15 \mathrm{~cm}$ of sediment at a depth of 8-10 m (total of $8 \mathrm{~L}$ of sediments) was taken by scuba diving. Sediments were placed in plastic buckets and gastrotrichs were extracted at the Universidade Estadual de Campinas (UNICAMP). The specimens were extracted from the sediment with isotonic $7 \% \mathrm{MgCl}_{2}$ using the anesthetization-decantation technique [5] in $1 \mathrm{~L}$ plastic Erlenmeyer flasks. Animals were decanted onto $35 \mu \mathrm{m}$ sieves and washed with ambient seawater into Petri dishes. Gastrotrichs were observed alive with a Leica EZ4 stereomicroscope and then transferred to glass slides for specific identification using a Zeiss Axio Imager M2 light microscope equipped with differential interference contrast optics (DIC) connected to a 
camera. Photomicrographs and measurements were taken using the software ZEN-blue edition. The position of anatomical characters is provided in percent units (U) of total body length (anterior tip of body (excluding cilia) $=\mathrm{U} 00$, posterior tip of body $=\mathrm{U100}$ ) [6]

\subsection{Phylogenetic Analysis}

\subsubsection{Ingroup Taxa}

All 13 formally described species within the genus Ptychostomella were used in the present analysis (Table 1).

\subsubsection{Outgroup Taxa}

The species Tetranchyroderma esarabdophorum Tongiorgi \& Balsamo, 1984 and T. quadritentaculatum Todaro, Balsamo \& Tongiorgi, 1992 were used as outgroups. Previous phylogenetic reconstructions placed Tetranchyroderma species as a sister group to the genus Ptychostomella $[1,7]$.

\subsubsection{Character Coding and Analysis}

We coded 12 morphological characters (Table 2). Most characters were coded as multistate or binary, but some were coded as contingent. Contingent coding [8], also called C coding [9] or conditional coding [10], first codes a binary character in one column of the matrix, and an additional code for the presence and absence of the feature in the next column. Non-applicable states were coded as '-' and unknown stated as '?' (Table 1).

Table 1. Matrix of morphological characters considered in the phylogenetic analysis of Ptychostomella. "?": unknown data;

"_": inapplicable character state.

\begin{tabular}{lllllllllllll}
\hline & $\mathbf{0}$ & $\mathbf{1}$ & $\mathbf{2}$ & $\mathbf{3}$ & $\mathbf{4}$ & $\mathbf{5}$ & $\mathbf{6}$ & $\mathbf{7}$ & $\mathbf{8}$ & $\mathbf{9}$ & $\mathbf{1 0}$ & References \\
\hline Tetranchyroderma esarabdophorum Tongiorgi \& Balsamo, 1984 & 2 & 0 & 1 & 1 & 0 & 1 & 1 & 3 & 1 & 0 & 0 & {$[11]$} \\
\hline Tetranchyroderma quadritentaculatum Todaro, Balsamo \& Tongiorgi, 1992 & 2 & 0 & 1 & 1 & 0 & 1 & 1 & 3 & 1 & 0 & 0 & {$[12]$} \\
\hline Ptychostomella bergensis Clausen, 1996 & 2 & 0 & 0 & 1 & 1 & 0 & 1 & 1 & 0 & 0 & 0 & {$[13]$} \\
\hline Ptychostomella brachycephala (Levi, 1954) & 1 & 0 & 0 & 1 & 0 & 0 & 1 & 1 & 0 & 0 & 0 & {$[14]$} \\
\hline Ptychostomella helana Roszczak, 1939 & 1 & 0 & 0 & 0 & 1 & 0 & 0 & - & 0 & 0 & 0 & {$[15]$} \\
\hline Ptychostomella jejuensis Lee, Hwang \& Chang, 2009 & 2 & 1 & 0 & 1 & 0 & 0 & 1 & 3 & 0 & 0 & 0 & {$[16]$} \\
\hline Ptychostomella higginsi Clausen, 2004 & 2 & 1 & 0 & 1 & 1 & 0 & 1 & 3 & 0 & 0 & 0 & {$[14]$} \\
\hline Ptychostomella lamelliphora Todaro, 2013 & 0 & 1 & 0 & 1 & 0 & 0 & 1 & 2 & 0 & 0 & 1 & {$[3]$} \\
\hline Ptychostomella lepidota Clausen, 2000 & 2 & 0 & 0 & 1 & 1 & 0 & 1 & 1 & 0 & 1 & 0 & {$[17]$} \\
\hline Ptychostomella mediterranea Remane, 1927 & 2 & 1 & 0 & 1 & 0 & 0 & 0 & - & 0 & 0 & 0 & {$[18]$} \\
\hline Ptychostomella ommatophora Remane, 1927 & 2 & 0 & 0 & $?$ & $?$ & 0 & 0 & - & 0 & 0 & 0 & {$[18]$} \\
\hline Ptychostomella orientalis Lee \& Chang, 2003 & 2 & 1 & 0 & 1 & 0 & 0 & 1 & 1 & 0 & 1 & 0 & {$[19]$} \\
\hline Ptychostomella papillata Lee \& Chang, 2003 & 2 & 0 & 0 & 1 & 0 & 0 & 1 & 3 & 0 & 0 & 0 & {$[19]$} \\
\hline Ptychostomella pectinata Remane, 1926 & 2 & 0 & 0 & 1 & 0 & 0 & 0 & - & 0 & 0 & 0 & {$[20]$} \\
\hline Ptychostomella tyrrhenica Hummon, Todaro \& Tongiorgi, 1993 & 2 & 1 & 0 & 1 & 0 & 0 & 1 & 3 & 0 & 0 & 0 & {$[21]$} \\
\hline Ptychostomella sebastiana sp. nov. & 1 & 0 & 1 & 1 & 0 & 0 & 1 & 1 & 0 & 0 & 1 & [present \\
study] & \\
\hline
\end{tabular}

Parsimony analysis was carried out using the computer program TNT under equal and implied weights $[22,23]$ to perform a 'sensitivity analysis' of the data in distinct situations. We used an exhaustive search for equal weights. For implied weight, the values of $\mathrm{K}$ were assigned to a 'not perfectly hierarchical' character fit of $85 \%, 86.11 \%, 87.22 \%, 88.33 \%$, $89.44 \%, 90.55 \%, 91.66 \%, 92.77 \%, 93.88 \%$, and $95 \%$ (script commands aaa 31085957 ). The authors in [24] proposed regular intervals fit/distortion values, which can be obtained under different K-values (Appendix S3 of [24]-file aaa.run). The software WINCLADA 1.00.08 [25] was used for character optimization and tree editing. 
Table 2. Morphological characters of Ptychostomella coded in the present analysis.

0. Cephalic sensorial organs-Lateral tentacle type

- 0 Short

- 1 Long

- 2 absent

1. Cephalic sensorial organs-Knob-like organ

- 0 absent

- 1 present

2. Cephalic sensorial organs-Dorsolateral tentacle

- 0 absent

- 1 present

3. Anterior adhesive tubes-Inserted along the mouth margin

- 0 absent

- 1 present

4. Anterior adhesive tubes-Inserted in a ventrolateral column

- 0 absent

- 1 present

5. Dorsal adhesive tubes

- 0 absent

- 1 present

6. Ventral adhesives at $\mathrm{U} 85$

- 0 absent

- 1 present

7. Ventral adhesives at U85-Type

- 0 Paired

- 1 Foot-like

- 2 Bulked with many adhesive tube

- 3 Single

8. Dorsal ornamentation-Ancres

- 0 absent

- 1 present

9. Dorsal ornamentation-Scale-like cuticular elevation

- 0 absent

- 1 present

10. Lateral ornamentation-Plates

- 0 absent

- 1 present

\subsection{Morphological Description of the Characters}

In this section, we present brief comments on the different characters. Schematic drawings of some structures were provided to better understand the assessment of homology hypotheses (Figure 1). Character numbers and transformation series in the following descriptions correspond to the character summary in Table 2 and data matrix in Table 1. 


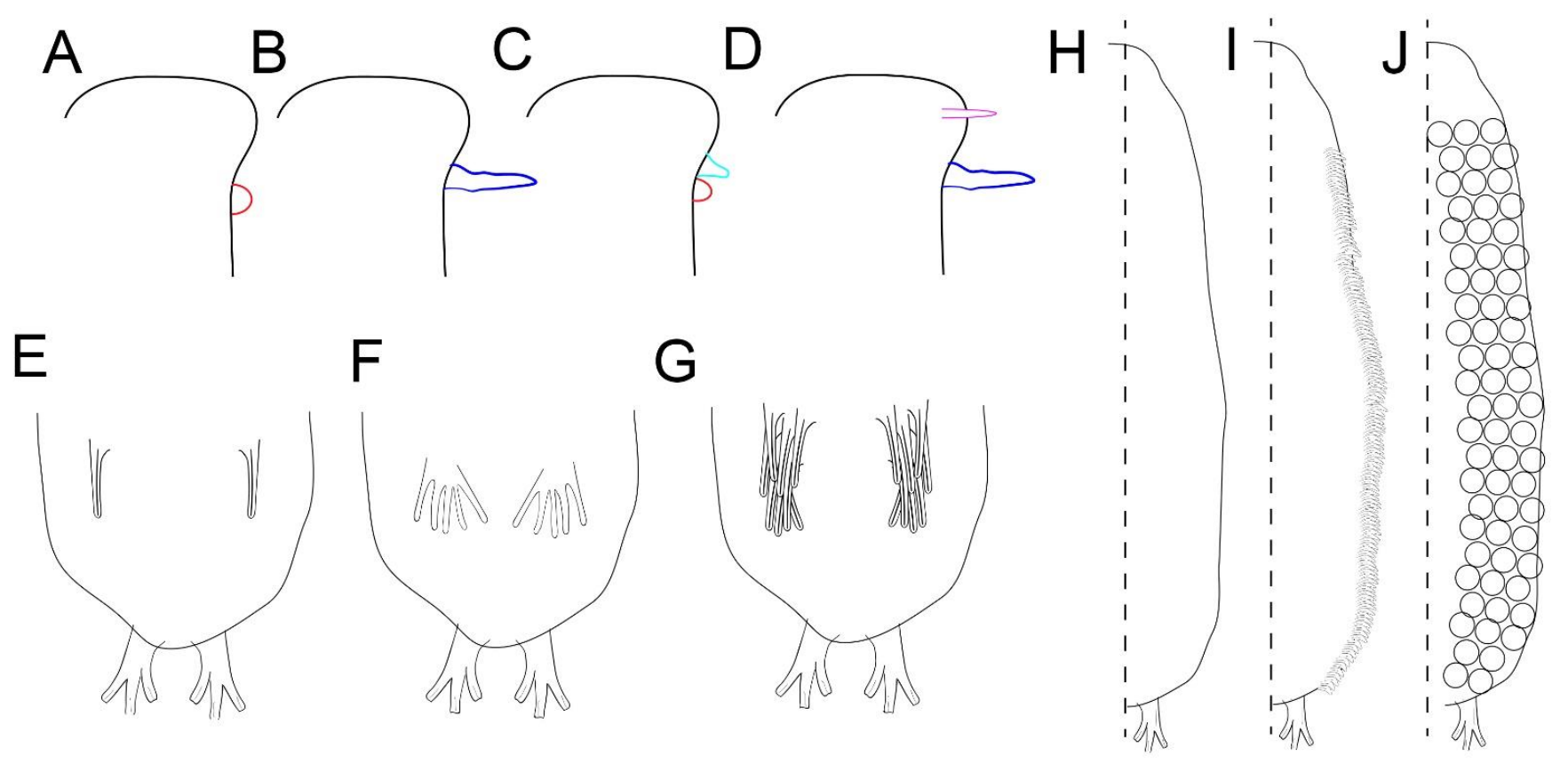

Figure 1. Schematic drawing of the morphological features. (A-D) Types and arrangements of cephalic sensorial organs: (A) Lateral knob (red); (B) Lateral large cephalic tentacle (dark blue); (C) Lateral knob (red) + lateral short cephalic tentacle (light blue); (D) Dorsolateral rod-like (pink) + lateral long (dark blue) tentacle. (E-G) Arrangement of TbV at U80 region: (E) Single adhesive tubes; (F) "Foot-like" tubes; (G) Bulkiness cluster of adhesive tubes. (H-J) Dorsal ornamentation:

(H) Smooth body surfaces (I) Subrectangular scales; (J) Scale-like cuticular elevations.

Cephalic sensorial organs. Two types of bilateral cephalic tentacles are present in Ptychostomella species: long and short tentacles. The long tentacles are 3-4 times larger than $\mathrm{TbA}$, and the short tentacles possess the same size as $\mathrm{TbA}$ (Figure 1B,D), which we believe to be equivalent to the same transformation series with two different states (character 0 ). There is also one type of rod-like dorsolateral cephalic tentacle (character 2) (Figure 1D) and one type of bilateral knob-like organ (character 1) (Figure 1A,C).

Ventral adhesive tubes at U85 region. The ventral adhesive tubes at the U85 region can be arranged in three different forms: paired tubes (character 7, state 0) (Figure 1E), foot-like with few adhesive tubes (character 7, state 3) (Figure 1F), and a bulkiness cluster of adhesive tubes (character 7, state 2) (Figure 1G).

Coverage of dorsal and dorsolateral body wall. The ornamentation can be present along all dorsal surfaces as scale-like cuticular elevations (Figure 1J) and subrectangular scales (Figure 1J) covering the lateral surfaces.

\section{Results}

\subsection{Taxonomic Account}

Order Macrodasyida Remane, 1925 [Rao \& Clausen, 1970]

Family Taumastodermatidae Remane, 1927

Subfamily Taumastodermatinae Remane, 1927

Genus Ptychostomella Remane, 1926

Ptychostomella sebastiana sp. nov.

Examined Material. Holotype. Adult, collected from Praia da Fome in São Sebastião, State of São Paulo, Brazil ( $23^{\circ} 45^{\prime} 24^{\prime \prime}$ S; $\left.45^{\circ} 21^{\prime} 1.5^{\prime \prime} \mathrm{W}\right)$, at $10 \mathrm{~m}$ depth, deposited at the Museu de Zoologia, Universidade Estadual de Campinas, Brazil, under accession number ZUECPIC: 432. Paratype. Subadult, collected from Praia da Fome in São Sebastião, State of São Paulo, Brazil ( $\left.23^{\circ} 45^{\prime} 24^{\prime \prime} \mathrm{S} ; 45^{\circ} 21^{\prime} 1.5^{\prime \prime} \mathrm{W}\right)$, at $10 \mathrm{~m}$ depth, deposited at the Museu de Zoologia, Universidade Estadual de Campinas, Brazil, under accession number ZUEC-PIC: 433. 
Etymology. The specific epithet sebastiana refers to the city of São Sebastião, where the specimens were sampled.

Repository: urn:lsid:zoobank.org:act:3918251C-3391-43B6-9E5F-FBE32B10EE20.

Diagnosis. A Ptychostomella with an adult length up to $250 \mu \mathrm{m}$; pharynx length up to $78 \mu \mathrm{m}$, with pharyngeal pores at base. PhIJ at U38; body with almost parallel sides and short, bilobed caudum. Head bearing paired club-shape lateral tentacles and a paired small "rod-like" tentacle at dorsolateral surface; few sensory hairs forming columns along lateral side of the body, scattered sensory hairs around the oral opening, few sensory hairs along the lateral tentacle surface and tufts at the tip of the dorsolateral tentacle; a great number of epidermal glands along the length of the body. Dorsal and ventral surfaces are generally smooth, except ventrolateral surfaces that are covered by subrectangular scales arranged in a column on each side of the body. Ten TbA arranged in groups of four on each side, and one of two at middle line on ventral surface $(4+2+4)$. Three TbL on each side of the body at $\mathrm{U} 12, \mathrm{U} 60$, and $\mathrm{U} 90 . \mathrm{TbV}$ noticeable in two distinct groups: four to five adhesive tubes spaced along the ventral surface from U45-U65 and paired "feet" with five adhesive tubes each at U83. Eleven TbP per side arranged as eight inserted laterally, two at the tip of the lobes, and one on the inner part of the lobe. Locomotory cirri covering the entire ventral surface of the body. Testis on the right side of the body, pyriform caudal organ, frontal organ above the caudal organ filled with spermatozoa, and presence of a dorsally placed egg in intestine the region.

Description. Adult holotype with $250 \mu \mathrm{m}$ in total length. Pharynx $78 \mu \mathrm{m}$ in length. Pharyngeal pores near the base, at U31; pharyngeo-intestinal junction at U38. Head bearing two paired tentacles: dorsolateral "rod-like" small tentacle with $12 \mu \mathrm{m}$ in length at U03 (Figures 2A, 3A and $4 \mathrm{~A}$ ), and a lateral club-shape tentacle with $25 \mu \mathrm{m}$ in total length at U8. Widths of the head/neck/trunk/caudal base, 40/50/53/30 $\mu \mathrm{m}$ at U07/U25/U46/U90, respectively. Oral opening with scattered sensory cilia along the entire margin. Sparse sensory cilia along the dorsal surface of the lateral tentacle and tufts of sensory cilia on the tip of the dorsolateral tentacle. Few sensory hairs forming columns along lateral sides of the body.

Cuticular armature. Dorsal and ventral surfaces apparently smooth. However, each ventrolateral side is covered by subrectangular scales with similar size $(3-4 \mu \mathrm{m})$ overlapping each other partially, forming a column running from U08 to U90 (Figures $2 B, C$ and $3 C$ ).

Adhesive tubes. Ten TbA arranged in $4+2+4$ at $\mathrm{U} 09,7 \mu \mathrm{m}$ in length laterally and medially (Figures $2 \mathrm{C}, 3 \mathrm{C}$ and $4 \mathrm{C})$. Three TbL per side (12 $\mu \mathrm{m}$ in length) inserting at U12, U60, and U90, respectively (Figures 2, 3A,B and $4 \mathrm{C}$ ). TbD, absent. TbV noticeable in two distinct groups: four to five spaced along the ventral surface from U45-U65 (8-13 $\mu \mathrm{m}$ in length) (Figures $2 \mathrm{C}$ and $3 \mathrm{C}$ ) and paired "feet" with five adhesive tubes each at U83 (12 $\mu \mathrm{m}$ in length) (Figures 2C, 3C and 4D). Eleven TbP per side arranged as eight inserted laterally (11 $\mu \mathrm{m}$ in length), two at tip of the lobes ( $6 \mu \mathrm{m}$ in length), and one flanking medially on the inner part of the caudal pedicle ( $7 \mu \mathrm{m}$ in length) (Figures $2,4 \mathrm{~B}$ and $5 \mathrm{~A})$. 

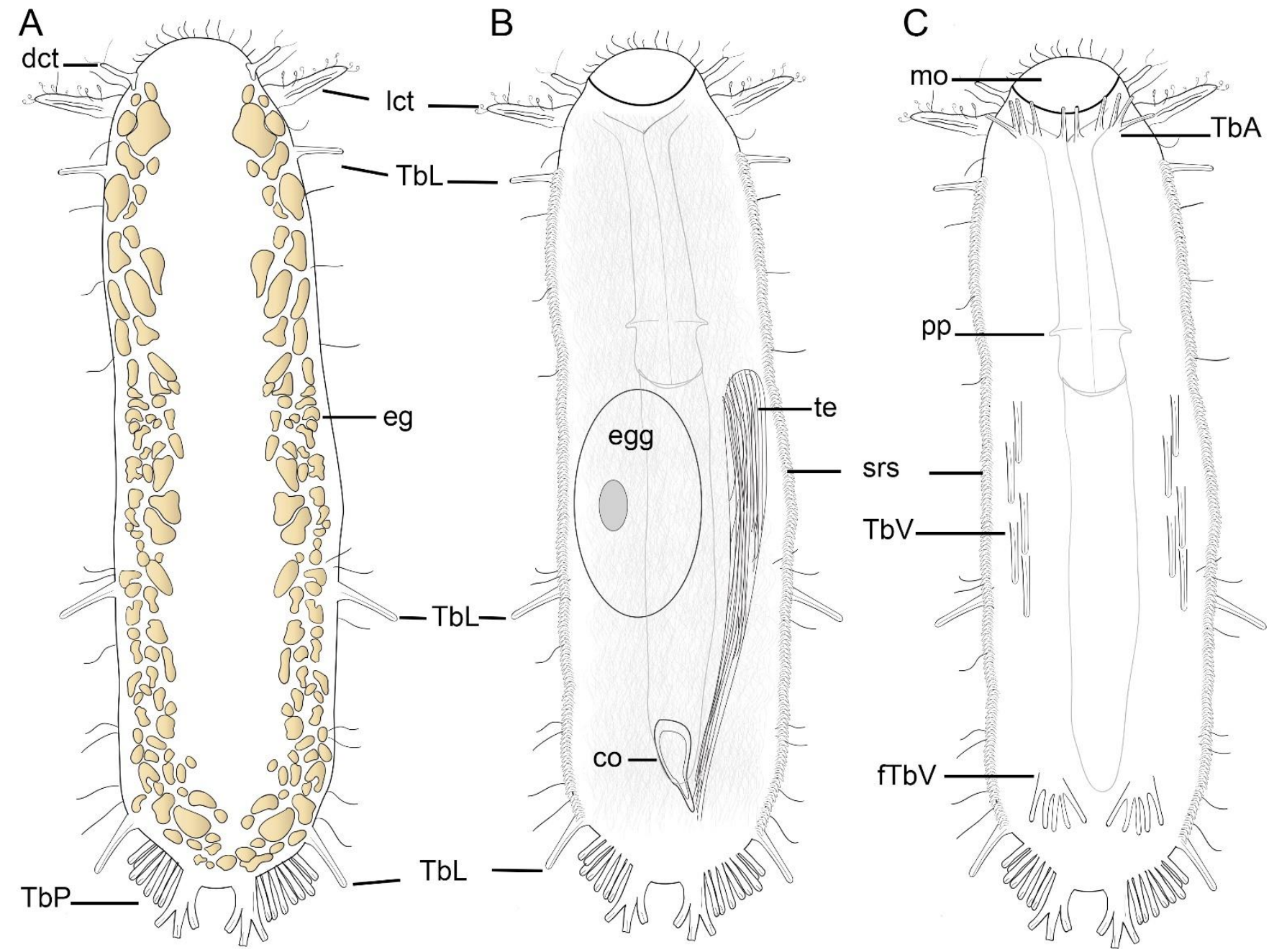

Figure 2. Schematic drawing of Ptychostomella sebastiana sp. nov. (A)—Dorsal body. (B)—Internal body. (C)—Ventral body. Abbreviations: co, caudal organ; dct, dorsal cephalic tentacle; eg, epidermal glands; fTbV, foot-like ventral adhesive tubes; lct, lateral cephalic tentacle; mo, mouth; pp, pharyngeal pores; srs, subrectangular scales; $\mathrm{TbA}$, anterior adhesive tubes; TbL, lateral adhesive tubes; TbP, posterior adhesive tubes; $\mathrm{TbV}$, ventral adhesive tubes; te, testis. 

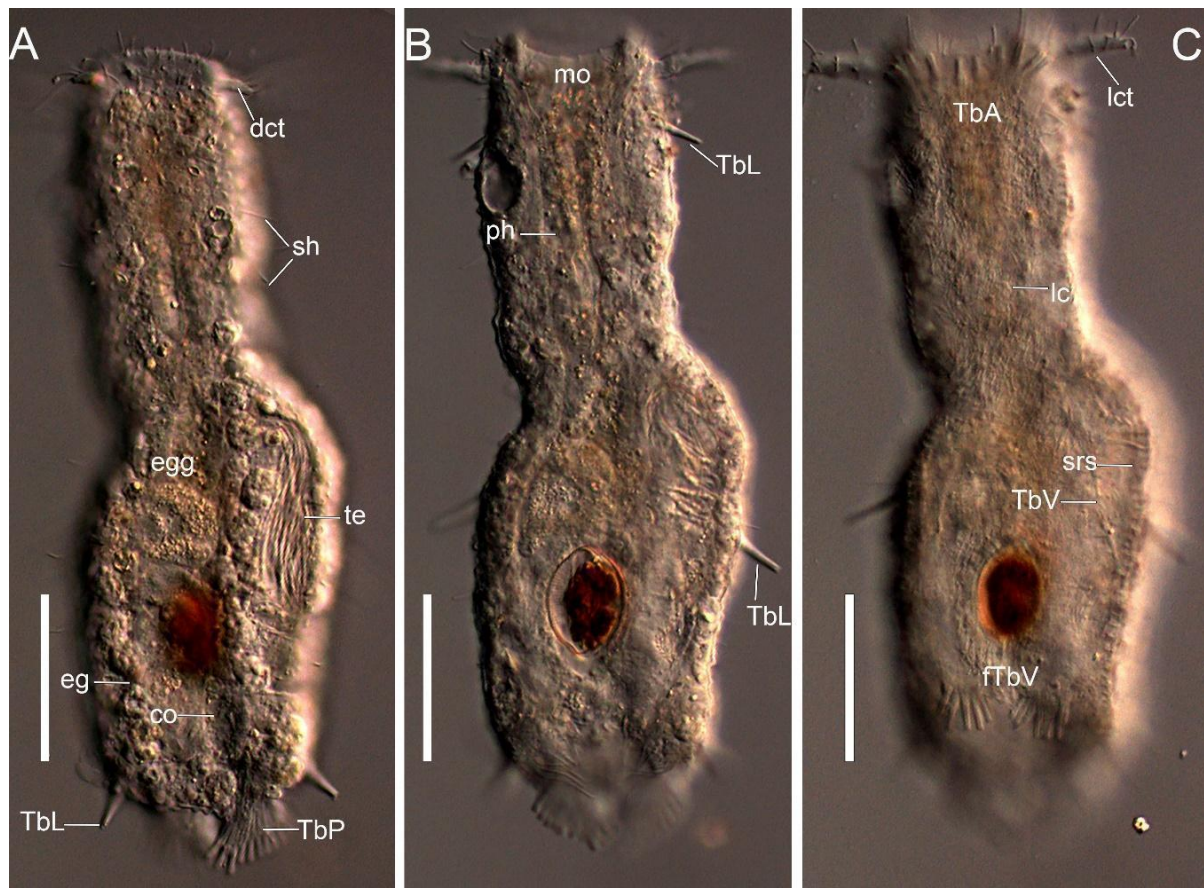

Figure 3. DIC photomicrographies of Ptychostomella sebastiana sp. nov. (A) Dorsal body. (B) Internal body. (C) Ventral body. Abbreviations: co, caudal organ; dct, dorsal cephalic tentacle; eg, epidermal glands; fTbV, foot-like ventral adhesive tubes; lc, locomotory cilia; lct, lateral cephalic tentacle; mo, mouth; ph, pharynx; sh, sensory hairs; srs, subrectangular scales; TbA, anterior adhesive tubes; $\mathrm{TbL}$, lateral adhesive tubes; $\mathrm{TbP}$, posterior adhesive tubes; $\mathrm{TbV}$, ventral adhesive tubes; te, testis. Scale bars: $50 \mu \mathrm{m}$.
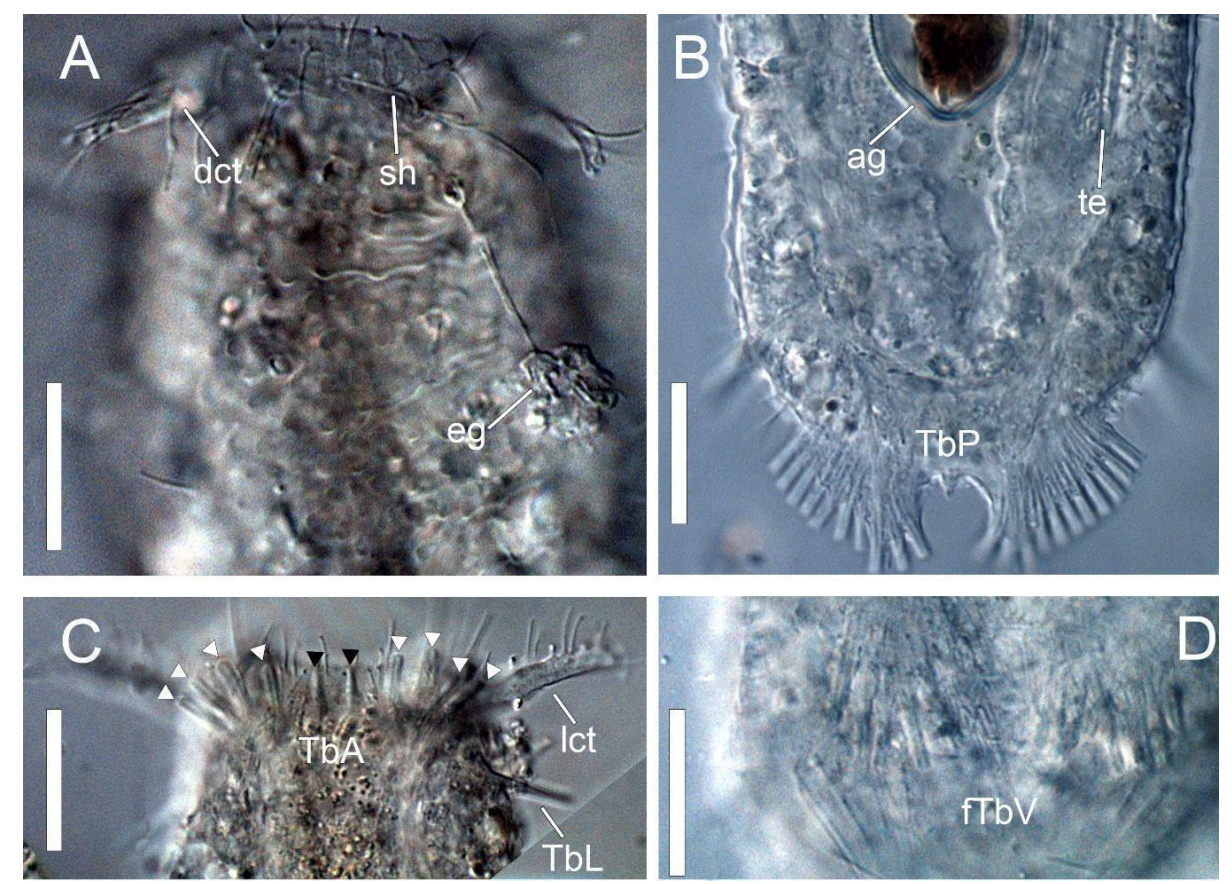

Figure 4. DIC photomicrographies of Ptychostomella sebastiana sp. nov. (A) Dorsal head surface. (B) Posterior end of body. (C) Close-up of TbA arrangement. (D) Close-up of foot-like ventral adhesive tubes. Abbreviations: ag, algae; dct, dorsal cephalic tentacle; eg, epidermal glands; fTbV, foot-like ventral adhesive tubes; lc, locomotory cilia; lct, lateral cephalic tentacle; sh, sensory hair; $\mathrm{TbA}$, anterior adhesive tubes; $\mathrm{TbL}$, lateral adhesive tubes; $\mathrm{TbP}$, posterior adhesive tubes; te, testis. Black triangles indicate central TbA; White triangles indicate lateral TbA. Scale bars: $50 \mu \mathrm{m}$. 

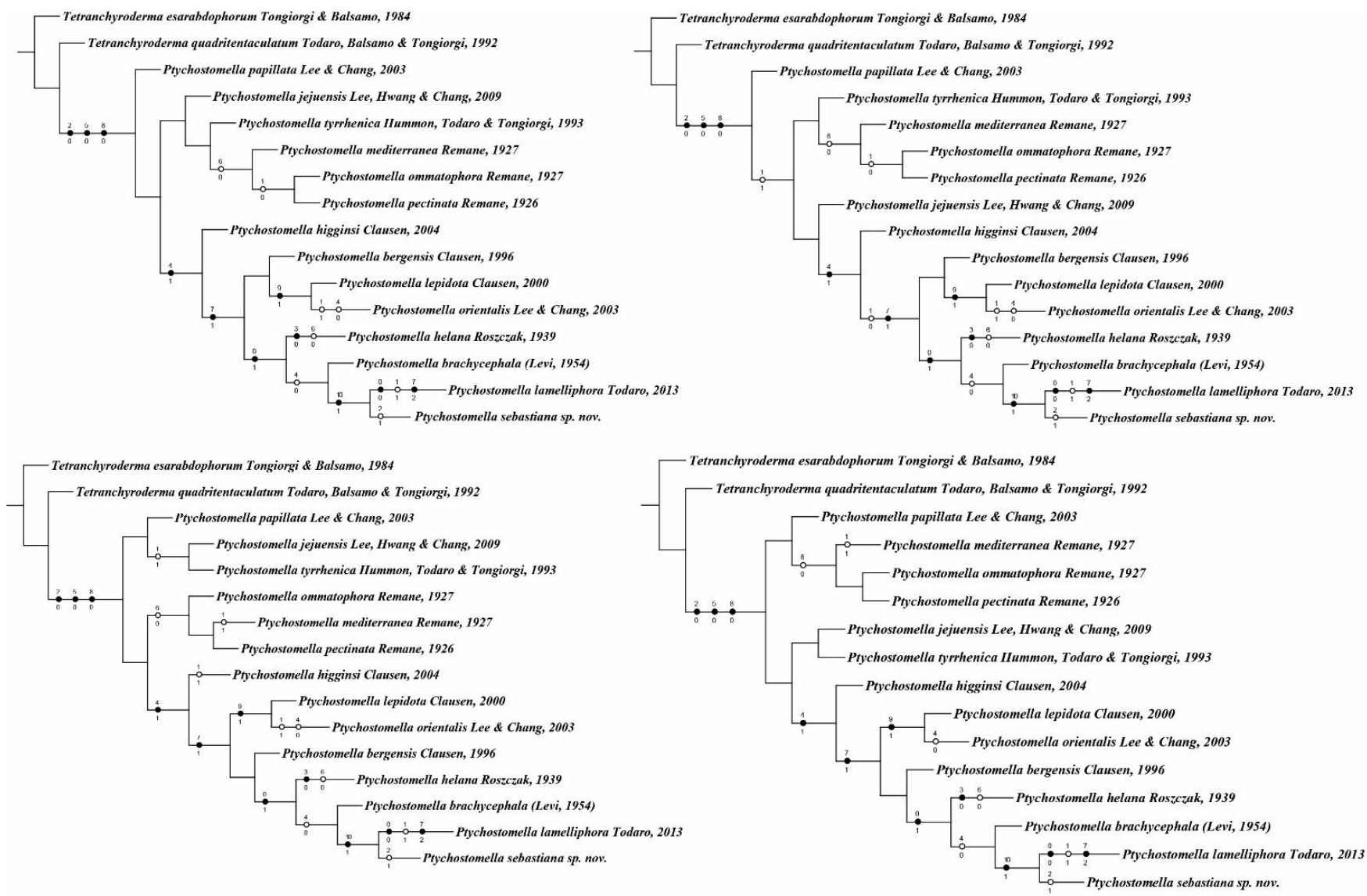

Figure 5. Most parsimonious trees obtained by implied weight analysis of the genus Ptychostomella. Black circles = synapomorphy; white circles = homoplasy. Numbers above branches define characters; numbers below branches are character states.

Ventral ciliation. A continuous, dense field of locomotory cilia that extend from the ventral border of the oral opening to the base of the caudal pedicles (Figure 3C).

Reproductive system. Testis on the right body side, pyriform caudal organ at U82; Eggs dorsal to the mid intestine (Figures $2 \mathrm{~B}$ and $3 \mathrm{~A}$ ).

Epidermal Glands. Numerous epidermal glands forming two columns along the lateral length of the body from U01, joining at caudal base U89 (Figures 2A and 4A).

Taxonomic Remarks

Ptychostomella sebastiana sp. nov. falls within a clade that includes P. lamelliophora, sharing the apomorphic feature of subrectangular scales on each lateral side of the body. However, the new species can be distinguished by the presence of adhesive tubes inserted laterally of the pedicles, $\mathrm{TbV}$ as foot-like instead of a cluster of high number of adhesive tubes at U85, and cephalic tentacle shape and arrangement (dorsolateral pairs of rod-like + lateral club-shape tentacles in the new species and lateral pairs knob-like + short cephalic tentacles in P. lamelliophora).

\subsection{Phylogenetic Analysis}

A total of 221 most parsimonious trees with 22 steps, $\mathrm{Ci}=59$ and $\mathrm{Ri}=68$, were obtained under equal weight analysis. Six MPTs (Figures 5 and 6) were recovered using implied weight on all K-values obtained from the used script and besides that, the present topologies were recovered from the unweighted MPTs. 


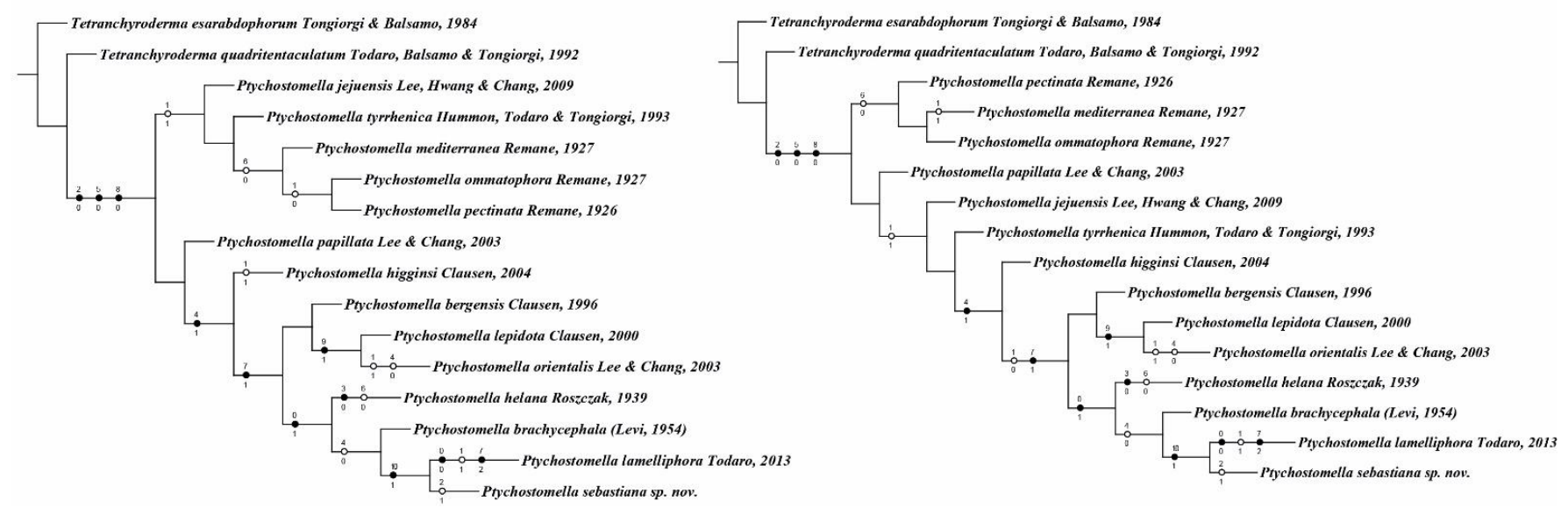

Figure 6. Most parsimonious trees obtained by implied weight analysis of the genus Ptychostomella. Black circles = synapomorphy; white circles = homoplasy. Numbers above branches define characters; numbers below branches are character states.

These six topologies presented five monophyletic groups that were recovered from the six MPTs and presented in the consensus tree (Figure 7). The first group, (P. higginsi (P. bergensis, (P. lepidota, P. orientallis), (P. helana (P. brachycephala (P. lamelliphora, $P$. sp. nov.))))) shares the synapomorphic presence of anterior adhesive tubes, inserted in a ventrolateral column (character 4, state 1). The second group is defined by the foot-like arrangement of ventral adhesive tubes at $\mathrm{U} 85$ (Figure 1F) of (P. bergensis (P. lepidota, P. orientallis) (P. helana (P. brachycephala (P. lamelliphora, $P$. sp. nov.)))), but the real position of $P$. bergensis is not clear. The third group, (P. lepidota, P. orientallis) is defined by the presence of cuticular elevations (Figure 1J) covering the dorsal body surface (character 9 , state 1 ). The monophyletic group (P. helana (P. brachycephala (P. lamelliphora, $P$. sp. nov.))) is defined by unique synapomorphy, the presence of bilateral long cephalic tentacles (character 0, state 1) (Figure 1B-D). The last monophyletic group is defined by the presence of lateral plates (subrectangular scales) (character 10, state 1) covering each lateral body surface of (P. lamelliphora, P. sp. nov.) (Figure 1I). 


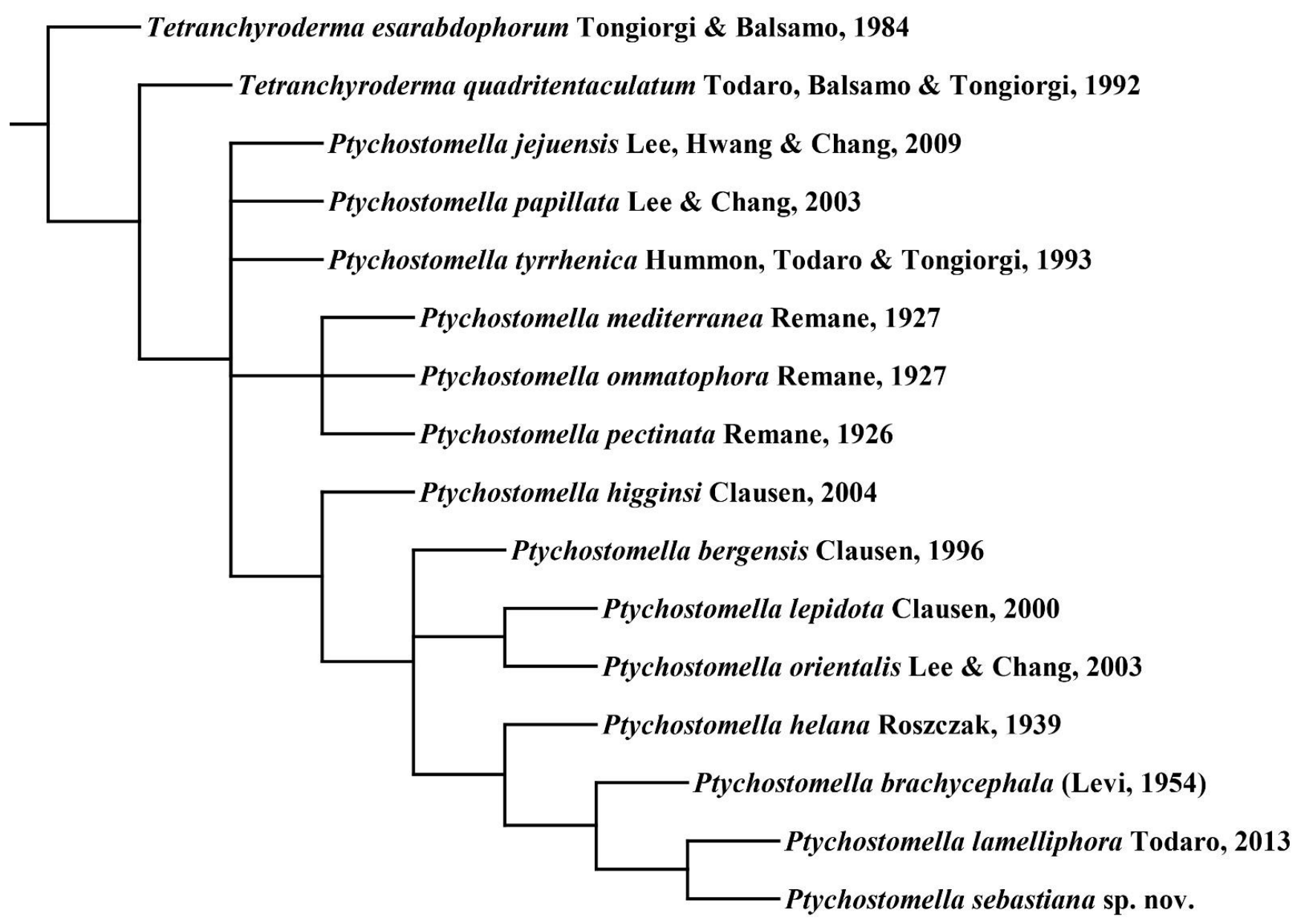

Figure 7. Consensus tree of the six most parsimonious trees obtained by implied weight analysis of the genus Ptychostomella.

\section{Discussion}

Thaumastodermatidae was originally described as a group of marine animals with an extraordinary ornamented cuticle [18]. However, it is possible to observe at least two exceptions within this group: Oregodasys Hummon, 2008, and Ptychostomella, which was previously recognized by a group of smooth cuticle species [3,17]. Specimens belonging to these two genera present some papillae covering the dorsal body surfaces when any kind of scale-like structures are not observed. However, since the first description of an ornamented Ptychostomella species conducted by [16], currently half of the species of this genus were described with ornamentation on the dorsal body surface. It is important to highlight that despite these species presenting some kind of cuticular ornamentation, it is necessary to be aware when a comparison is made between the structures, since they cannot be properly homologous, for example, scales and papillae are not formed by the same biological process and cannot be considered a state of the same character. Due to this, we decided not to use papilla as cuticular ornamentations, since among the thaumastodematids it is possible to observe this feature on other smooth bodied species, where it is not treated as ornamentation (e.g., Oregodasys). There were two types of cuticular ornamentations that were considered: a rounded scale-like ornamentation embossed on the dorsal and lateral surfaces $[17,19]$, and subrectangular scales covering each lateral surface of the body [3]. In our analysis, the smooth dorsal body surfaces appeared as a plesiomorphic state, and some kind of cuticular cover is homoplastic, arising in two distinct moments in the evolution of the group.

Another important feature is the presence of a foot-like TbV among the Ptychostomella specimens. As pointed out by [3], this feature is not a novelty among the thaumastoder- 
matids, but it was important to define a monophyletic group in our analysis. This feature appears to evolve from a plesiomorphic condition of a single paired adhesive tube to a synapomorphic condition foot-like structure with four or five tubes. The autapomorphy bulkiness clusters of TBV in P. lamelliophora are derived from the foot-like TbV. The presence of these $\mathrm{TbV}$ arrangements could be related to the type of sandy beach that they were present in (high, medium, low) or to a reproductive strategy [3].

A phylogenetic analysis based on morphological data was previously performed for two genera of Thaumastodermatidae, Thaumastoderma [26], and Pseudostomella [27]. These analyses were carried out using 37 and 33 morphological characters, respectively, and the monophyly of these groups was recovered in the same way as that proposed by phylogenetic analysis using molecular data [1], and the internal relationship of both taxa were well resolved. Despite that, we were able to ascertain that Ptychostomella is monophyletic, and we listed only 11 characters, but they did not provide the same phylogenetic signals or the internal support as observed in Thaumastoderma and Pseudostomella [26,27]. This low phylogenetic signal does not allow us to infer hypotheses about the biogeographic distribution of the Ptychostomella species as proposed by [27] and regarding the distributional pattern since, for the moment, we only have the sampling locations of all species (Table S1, Figure S1). Acquisition of information on morphological structures of Ptychostomella specimens is mainly done by optical microscopy and this technique addresses a low number of external morphological characters. However, as pointed out by [28], to obtain detailed morphological information on the external and internal morphology it is required to use other techniques such as scanning electron microscopy (SEM), transmission electron microscopy (TEM), confocal laser scanning microscopy (cLSM) combined with immunohistochemistry, and X-ray microtomography (Micro-CT). Beyond this, it is necessary to increase the number of the outgroup with non-scaled and scaled thaumastodermatids in future phylogenetic analyses to further test the monophyly of this taxon.

Supplementary Materials: The following are available online at https:/ /www.mdpi.com/article/10 .3390/taxonomy1040022/s1, Figure S1: Global distribution of Ptychostomella species, Table S1: List of Ptychostomella species with sampling biogeographic records.

Author Contributions: Conceptualization, T.Q.A. and A.R.S.G.; Methodology, T.Q.A. and A.R.S.G.; Software, T.Q.A. and A.R.S.G.; Formal analysis, T.Q.A. and A.R.S.G.; Investigation, T.Q.A.; Resources, A.R.S.G.; Data curation, T.Q.A. and A.R.S.G.; Writing—original draft preparation, T.Q.A. and A.R.S.G.; Writing-review and editing, T.Q.A. and A.R.S.G.; Visualization, T.Q.A. and A.R.S.G.; Supervision, A.R.S.G.; Project administration, A.R.S.G.; Funding acquisition, A.R.S.G. Both authors have read and agreed to the published version of the manuscript.

Funding: This research was funded by the São Paulo Research Foundation-FAPESP, grant numbers 2014/23856-0 and 2018/11166-0.

Data Availability Statement: The data of geographic location of all Ptychostomella species presented in this study are openly available in the supplementary material of this study.

Acknowledgments: We are grateful to the two anonymous reviewers for their constructive criticism that improved the first version of the manuscript and Yasmina Shah Esmaeil for editing the English text.

Conflicts of Interest: The authors declare no conflict of interest.

\section{References}

1. Todaro, M.A.; Kånneby, T.; Dal Zotto, M.; Jondelius, U. Phylogeny of Thaumastodermatidae (Gastrotricha: Macrodasyida) inferred from nuclear and mitochondrial sequence data. PLoS ONE 2011, 6, e0017892. [CrossRef]

2. Todaro, M.A. Marine and Freshwater Gastrotricha. Available online: http:/ / www.gastrotricha.unimore.it (accessed on 30 September 2021).

3. Todaro, M. A new non-naked species of Ptychostomella (Gastrotricha) from Brazil. Zookeys 2013, 289, 13-24. [CrossRef] [PubMed]

4. Ruppert, E.E. Gastrotricha. In Introduction to the Study of Meiofauna; Higgins, R.P., Thiel, H., Eds.; Smithsonian Institution Press: Washington, DC, USA, 1988; pp. 302-321.

5. Pfannkuche, O.; Thiel, H. Sampling processing. In Introduction to the Study Meiofauna; Higgins, R.P., Thiel, H., Eds.; Smithsonian Institution Press: Washington, DC, USA, 1988; Volume 1, pp. 134-145. 
6. Hummon, W.D.; Balsamo, M.; Todaro, M.A. Italian marine Gastrotricha: I. Six new and one redescribed species of Chaetonotida. Boll. Zool. 1992, 59, 499-516. [CrossRef]

7. Bosco, I.; Lourenço, A.P.; Guidi, L.; Balsamo, M.; Hochberg, R.; Garraffoni, A.R.S. Integrative description of a new species of Acanthodasys Remane, 1927 (Gastrotricha, Macrodasyida, Thaumastodermatidae) based on four distinct morphological techniques and molecular data. Zool. Anz. 2020, 286, 31-42. [CrossRef]

8. Forey, P.L.; Kitching, I.J. Experiments in coding multistate characters. In Homology and Systematics: Coding Characters for Phylogenetic Analysis; Scotland, R., Pennington, T., Eds.; Taylor \& Francis: London, UK, 2000; pp. 54-80.

9. Pleijel, F. On character coding for phylogeny reconstruction. Cladistics 1995, 11, 309-315. [CrossRef]

10. Hawkins, J.A.; Hughes, C.E.; Scotland, R.W. Primary Homology Assessment, Characters and Character States. Cladistics 1997, 13, 275-283. [CrossRef]

11. Tongiorgi, P.; Balsamo, M. A new Tetranchyroderma species (Gastrotricha, Macrodasyoidea) from the Adriatic coast. Boll. Zool. 1984, 51, 335-338. [CrossRef]

12. Balsamo, M.; Todaro, M.A.; Tongiorgi, P. Marine gastrotrichs from the Tuscan achipelago (Tyrrhenian Sea): II. Chaetonotida, with description of three new species. Boll. Zool. 1992, 59, 487-498. [CrossRef]

13. Clausen, C. Three new species of Gastrotricha Macrodasyida from the Bergenarea, Western Norway. Sarsia 1996, 81, 119-219. [CrossRef]

14. Clausen, C. Gastrotricha from the Faroe Bank. Sarsia 2004, 89, 423-458. [CrossRef]

15. Roszczak, R. Die Psammitgastrotricha des polnischen Ostseestrandes. Zool. Pol. 1939, 4, 1-24.

16. Lee, J.M.; WookHwang, U.; Chang, C.Y. A new gastrotrich species of the genus Ptychostomella (macrodasyida, thaumastodermatidae) from south korea. Anim. Cells Syst. 2009, 13, 25-30. [CrossRef]

17. Clausen, C.; Båmstedt, U. Gastrotricha Macrodasyida from the Tromsø region, northern Norway. Sarsia 2000, 85, 357-384. [CrossRef]

18. Remane, A. Neue Gastrotricha Macrodasyoidea. Zool. Jahrb. Abt. Syst. Ökologie Geogr. Tiere 1927, 54, $230-242$.

19. Lee, J.M.; Chang, C.Y. Two New Marine Gastrotrichs of the Genus Ptychostomella (Macrodasyida, Thaumastodermatidae) from South Korea. Zool. Sci. 2003, 20, 481-489. [CrossRef] [PubMed]

20. Remane, A. Morphologie und verwandtschaftsbeziehungen der aberranten gastrotrichen I. Z. Morphol. Ökologie Tiere 1926, 5, 625-754. [CrossRef]

21. Hummon, W.D.; Tod Aro, M.A.; Tongiorgi, P. Italian marine gastrotricha: II. one new genus and ten new species of macrodasyida. Bolletino Zool. 1993, 60, 109-127. [CrossRef]

22. Goloboff, P.A.; Farris, J.S.; Nixon, K.C. TNT: Tree Analysis Using New Technology. Syst. Biol. 2003, 54, $176-178$.

23. Goloboff, P.A.; Farris, J.S.; Nixon, K.C. TNT, a free program for phylogenetic analysis. Cladistics 2008, 24, 774-786. [CrossRef]

24. Marcos Mirande, J. Weighted parsimony phylogeny of the family Characidae (Teleostei: Characiformes). Cladistics 2009, 25, 574613. [CrossRef]

25. Nixon, K.C. WinClada Version. 1.00.08. Published by the Author. Ithaca, N.Y. 2002. Available online: http:/ / www.cladistics.com/ (accessed on 16 February 2007).

26. Kieneke, A. A new species of Thaumastoderma (Gastrotricha: Macrodasyida) from the Antarctic deep sea with a phylogenetic analysis of the whole genus. J. Mar. Biol. Assoc. UK 2010, 90, 575-584. [CrossRef]

27. Garraffoni, A.R.S.; Araújo, T.Q. Phylogeny of Pseudostomella Swedmark, 1956 (Gastrotricha: Macrodasyida) based on morphological data and first insights on the historical biogeography of Thaumastodermatidae. Proc. Biol. Soc. Washingt. 2017, 130, $222-238$. [CrossRef]

28. Fonseca, G.; Fontaneto, D.; Di Domenico, M. Addressing biodiversity shortfalls in meiofauna. J. Exp. Mar. Biol. Ecol. 2018, 502, 26-38. [CrossRef] 